\title{
Lr46: A Gene Conferring Slow-Rusting Resistance to Leaf Rust in Wheat
}

\author{
R. P. Singh, A. Mujeeb-Kazi, and J. Huerta-Espino
}

First and second authors: International Maize and Wheat Improvement Center (CIMMYT), Lisboa 27, Apartado Postal 6-641, 0660 Mexico, D.F.; and third author: SARH, INIFAP, CIANO, Km. 12 Carretera Norman E. Borlaug, Apartado Postal 515, 8500, Ciudad Obregon, Sonora, Mexico. Accepted for publication 4 June 1998.

\begin{abstract}
Singh, R. P., Mujeeb-Kazi, A., and Huerta-Espino, J. 1998. Lr46: A gene conferring slow-rusting resistance to leaf rust in wheat. Phytopathology 88:890-894.

Wheat (Triticum aestivum) cultivar Pavon 76 carries slow-rusting resistance to leaf rust that has remained effective in Mexico since its release in 1976. 'Pavon 76' was crossed with two leaf rust-susceptible wheat cultivars, Jupateco $73 \mathrm{~S}$ and Avocet $\mathrm{S}$, and between 118 and 148 individual $\mathrm{F}_{2}$ plant-derived $\mathrm{F}_{3}$ and $\mathrm{F}_{5}$ lines were evaluated for adult-plant leaf rust

cated that the resistance was based on two genes with additive effects. Monosomic analysis was carried out to determine the chromosomal locations of the resistance genes. For this purpose, two or three backcrossderived cytogenetic populations were developed by crossing 'Pavon 76' with a monosomic series of adult-plant leaf rust-susceptible cultivar Lalbahadur. Evaluation of such $\mathrm{BC}_{2} \mathrm{~F}_{3}$ and $\mathrm{BC}_{3} \mathrm{~F}_{3}$ lines from 16 confirmed 'Lalbahadur' monosomics indicated that one slow-rusting gene was located in chromosome 1B of 'Pavon 76'. This gene, designated as Lr46, is the second named gene involved in slow-rusting resistance to leaf rust in wheat.
\end{abstract} resistance at two field sites in Mexico during different seasons. Evaluation of $F_{1}$ plants and parents indicated that the slow-rusting resistance was partially dominant. Segregation in the $F_{3}$ and $F_{5}$ generations indi-
Additional keywords: Puccinia recondita.
Leaf rust, caused by Puccinia recondita Roberge ex Desmaz. f. sp. tritici (Eriks. \& E. Henn.) D.M. Henderson, is an important disease of wheat (Triticum aestivum L.) worldwide. Genetic resistance is the most economical and environmentally safe measure to reduce crop losses. Sayre et al. (13) estimated the genetic progress in reducing grain yield losses through breeding for leaf rust resistance in International Maize and Wheat Improvement Center (CIMMYT) germ plasm-derived Mexican wheat cultivars. Average grain yield losses due to leaf rust of these cultivars, released between 1966 and 1988, ranged between 6.6 and $62.7 \%$ for immune 'Oasis 86' and most susceptible 'Jupateco 73', respectively. 'Pavon 76', released in 1976 , displayed slow-rusting or partial resistance $(3,10)$ that has remained effective in Mexico and other parts of the world where it has been released and grown. Relative area under the disease progress curve of 'Pavon 76' was only 9\% of 'Jupateco 73', with a $17 \%$ loss of the grain yield compared with the yield in fungicide-protected plots. Singh and Rajaram (21) postulated the presence of genes $\mathrm{Lrl}, \mathrm{Lr} 10$, and $\mathrm{Lrl3}$ in 'Pavon 76' and indicated that the slow-rusting resistance to Mexican races of $P$. recondita $\mathrm{f}$. sp. tritici must be conferred by additional unknown genes, because the races used in their studies carried virulences for all of the above $\mathrm{Lr}$ genes. Gene Lr34 is known to confer slow-rusting resistance to Mexican races of $P$. recondita f. sp. tritici (19); however, Singh (18) indicated its absence in 'Pavon 76'.

The objectives of our study were (i) to determine the number and type of genes that confer adult-plant resistance to $P$. recondita f. sp. tritici in Mexican spring wheat cultivar Pavon 76, and (ii) to identify the chromosomes carrying genes involved in the adultplant resistance of 'Pavon 76'.

\section{MATERIALS AND METHODS}

Genetic analysis. 'Pavon 76' was crossed with two susceptible wheat cultivars, Jupateco $73 \mathrm{~S}$ and Avocet S. The pedigrees of these

Corresponding author: R. P. Singh; E-mail address: rsingh@ cimmyt.mx

Publication no. P-1998-0716-01R

(C) 1998 The American Phytopathological Society wheats are given in Table 1 . A total of 118 individual $F_{2}$ plantderived $F_{3}$ and $F_{5}$ lines from the cross 'Jupateco 73S' $\times$ 'Pavon 76' and $148 \mathrm{~F}_{3}$ and $146 \mathrm{~F}_{5}$ lines from the cross 'Avocet $S$ ' $\times$ 'Pavon 76' were used in the adult-plant inheritance studies. The $\mathrm{F}_{5}$ lines were obtained by harvesting a random spike from each $\mathrm{F}_{3}$ line and a random plant from each $\mathrm{F}_{4}$ line. The $\mathrm{F}_{3}$ lines from 'Jupateco $73 \mathrm{~S}$ ' $\times$ 'Pavon 76' were grown at CIMMYT's highland research station at El Batan (Mexico State) near Mexico City during the 1991 crop season, which begins in mid-May. The $F_{1}$ seeds from the above cross were included in the planting. Other populations were grown at CIMMYT's research station at Ciudad Obregon (Sonora State) in northwestern Mexico during different crop seasons (Table 2). At this site, sowing was done during the last week of November. Approximately 60 seeds of each $\mathrm{F}_{3}$ or $\mathrm{F}_{5}$ line were sown in $75-\mathrm{cm}-$ wide paired-row plots, $1 \mathrm{~m}$ in length, with $20-\mathrm{cm}$ row spacing and a $50-\mathrm{cm}$ pathway between plots. Rows of the two parents were planted at the beginning of each population. The leaf rust epidemic was initiated approximately 6 weeks after sowing by spraying spreader rows of highly susceptible cultivar Morocco, planted on one side of the plots in the pathway, with a suspension of urediniospore in a light-weight mineral oil (Soltrol 170; Phillips 66 Co., Bartlesville, OK). Both field sites (El Batan and Ciudad Obregon) have a favorable environment for leaf rust development. Mexican $P$. recondita $\mathrm{f}$. $\mathrm{sp}$. tritici race $\mathrm{TBD} / \mathrm{TM}$ was used for studies during the 1991 and 1992 to 1993 seasons, and race MCJ/SP was used for studies during the 1995 to 1996 and 1996 to 1997 seasons (Table 2). Nomenclature of these races is based on Singh (16) with the following avirulence/virulence formula: TBD/TM, $L r 3 \mathrm{ka}$, $9,11,16,19,21,23,24,25,26,29,30,32,33 / 1,2 a, 2 b, 2 c, 3,3 b g, 10,12$, $13,14 a, 14 b, 15,17,18,20,22 b, 27+31,28$; and MCJ/SP, Lr2a,2b,2c, $3 \mathrm{ka}, 9,16,19,21,24,25,28,29,30,32,33 / 1,3,3 \mathrm{bg}, 10,11,12,13,14 a, 14 b$, $15,17,18,20,22 b, 23,26,27+31$. Race TBD/TM was one of the predominant races in Mexico before 1994. Race MCJ/SP and a few variants related to it appeared in Mexico during the 1994 to 1995 season and have replaced the earlier races (6). Vacuum-dried (12) urediniospores of these races are stored at CIMMYT. Fresh inoculum obtained by multiplying urediniospores on the susceptible cultivar Morocco in the greenhouse was used in various studies. 
The visual estimations of adult-plant leaf rust severities were based on the modified Cobb scale (11). The host response to infection (reaction) followed the scale described by Roelfs et al. (12). The first leaf rust severity and reaction were recorded on flag leaves at about the milk stage of grain development, when the susceptible parent displayed a response between $80 \mathrm{~S}$ and $100 \mathrm{~S}$. The severity range (the most resistant and most susceptible plant) was recorded for $\mathrm{F}_{3}$ and $\mathrm{F}_{5}$ lines; whereas, for $\mathrm{F}_{5}$ lines, average leaf rust severity was also visually estimated. The $F_{3}$ and $F_{5}$ lines were evaluated a second time approximately 12 to 15 days after the first evaluation, when leaf rust had killed leaves of the susceptible parent used in the cross. Our previous studies $(20,22)$ have shown that the timing of the first rating is critical to identify plants or lines that are similar in susceptibility level to the susceptible parent, whereas the second rating is critical to identify plants or lines similar in resistance levels to the resistant parent. On the basis of the two data sets, the $\mathrm{F}_{3}$ and $\mathrm{F}_{5}$ lines were classified into four categories: homozygous parental-type resistance (HPTR); homozygous parentaltype susceptibility (HPTS); either segregating or homozygous for disease levels higher than that of the resistant parent, but less than that of the susceptible parent (SegI); and segregating with disease

TABLE 1. Wheat cultivars, 'Lalbahadur' monosomics (Lalb Mono), their pedigrees, and reaction range to leaf rust tested in the field over four seasons

\begin{tabular}{|c|c|c|}
\hline $\begin{array}{l}\text { Cultivar/ } \\
\text { monosomic }\end{array}$ & Pedigree & $\begin{array}{l}\text { Leaf rust reaction } \\
\text { range }^{\mathrm{a}}\end{array}$ \\
\hline 'Pavon 76' & $\mathrm{Vcm} / / \mathrm{Cno} / 7 \mathrm{C} / 3 / \mathrm{Kal} / \mathrm{Bb}$ & 5-10MSS \\
\hline 'Jupateco 73S' & II12300//Lr64/8156/3/Nor & $100 \mathrm{~S}$ \\
\hline 'Avocet S' & WW119/WW15//Egret & $80-100 \mathrm{~S}$ \\
\hline 'Lalbahadur' & S54723/RS31 & $100 \mathrm{~S}$ \\
\hline Lalb Mono 1A & Mx86.98.1/Kal//5*Lalb & $100 \mathrm{~S}$ \\
\hline Lalb Mono 2A & Oxley Mono 2A/Kal $/ / 5 *$ Lalb & $\operatorname{Seg}^{\mathrm{b}}(5$ \\
\hline Lalb Mono 3A & Mx86.96.6/Kal//5*Lalb & $100 \mathrm{~S}$ \\
\hline Lalb Mono 4A & Oxley Mono $4 \mathrm{~A} / \mathrm{Kal} / / 5 * \mathrm{Lalb}$ & $100 \mathrm{~S}$ \\
\hline Lalb Mono 5A & Oxley Mono 5A/Kal $/ / 5 *$ Lalb & $100 \mathrm{~S}$ \\
\hline Lalb Mono 6A & Oxley Mono $6 \mathrm{~A} / \mathrm{Kal} / / 5 *$ Lalb & $100 \mathrm{~S}$ \\
\hline Lalb Mono 7A & Oxley Mono 7A/Kal//5*Lalb & $100 \mathrm{~S}$ \\
\hline Lalb Mono 1B & Oxley Mono 1B/Kal//5*Lalb & $100 \mathrm{~S}$ \\
\hline Lalb Mono 2B & Mx86.97.2/Kal//4*Lalb & $100 \mathrm{~S}$ \\
\hline Lalb Mono 3B & Oxley Mono 3B/Kal $/ / 5^{*}$ Lalb & $100 \mathrm{~S}$ \\
\hline Lalb Mono 4B & Oxley Mono 4B/Kal $/ / 5 *$ Lalb & $100 \mathrm{~S}$ \\
\hline Lalb Mono 5B & Oxley Mono 5B/Kal //5*Lalb & $100 \mathrm{~S}$ \\
\hline Lalb Mono 6B & Oxley Mono 6B/Kal//5*Lalb & $100 \mathrm{~S}$ \\
\hline Lalb Mono 7B & Oxley Mono 7B/Kal//5*Lalb & $100 \mathrm{~S}$ \\
\hline Lalb Mono 1D & Mx86.100.2/Kal/5*Lalb & $100 \mathrm{~S}$ \\
\hline Lalb Mono 2D & Egret Mono 2D/CSP44//Kal/3/5*Lalb & 10-20MSS \\
\hline Lalb Mono 3D & Oxley Mono 3D/Kal $/ / 5 *$ Lalb & $100 \mathrm{~S}$ \\
\hline Lalb Mono 4D & Egret Mono 4D/Kal//2*Lalb & 5-10MSS \\
\hline Lalb Mono 5D & Mx86.101.6/Kal//5*Lalb & Seg (5-20MSS, 100S) \\
\hline Lalb Mono 6D & Oxley Mono 6D/Kal $/ 5 *$ Lalb & $100 \mathrm{~S}$ \\
\hline Lalb Mono 7D & Mx86.106.4/Kal//4*Lalb & $100 \mathrm{~S}$ \\
\hline
\end{tabular}

${ }^{\mathrm{a}}$ Leaf rust reaction has two components: percent severity based on the modified Cobb scale (11) and response to infection based on Roelfs et al. (12), where MSS = moderately susceptible to susceptible and $\mathrm{S}=$ susceptible response to infection.

${ }^{\mathrm{b}} \mathrm{Seg}=$ segregating. levels reaching the susceptible parent's response (SegS). Chi-square analyses were carried out to compare the distribution of $F_{3}$ and $F_{5}$ phenotypic frequencies with those expected for segregation of two additive genes (Table 2).

Chromosomal location of resistance genes. Since 'Chinese Spring' carries adult-plant leaf rust resistance genes Lr12 and Lr34 (5), its aneuploids (14) could not be used for chromosomal location work. Therefore, we used a monosomic series of adult-plant leaf rust-susceptible Indian cultivar Lalbahabur, which was developed and provided by R. A. McIntosh (Plant Breeding Institute, University of Sydney, Australia).

Seeds of the 21 'Lalbahadur' monosomics (Table 1) were germinated in petri plates in the dark at room temperature. Root tips were collected from each germinating seedling, which had been pretreated with colchicine plus dimethylsulfoxide for $3.5 \mathrm{~h}$ and fixed in $2 \%$ aceto-orcein (9). Plants with 41 chromosomes were retained and transplanted to the field. Crosses of 'Pavon 76' (used as the male parent) were made with each of the 21 monosomics. $F_{1}$ seeds from the 21 crosses were germinated, and plants with $2 n=41$ were identified by mitotic root tip chromosomal counts. These monosomic plants were used as male parents in backcrosses with the corresponding $2 n=41$ 'Lalbahadur' monosomics to develop a chromosome substitution series (15). Two to three backcrosses were made as described above. Two $\mathrm{BC}_{2}$ (or, in three cases, $\mathrm{BC}_{1}$ ) monosomic plants from each of the 21 crosses were selfed to obtain $\mathrm{F}_{2}$ populations from these backcrosses. About 20 space-sown $(15 \mathrm{~cm}$ between plants) plants of each of the above $\mathrm{F}_{2}$ populations were grown to develop backcross $\mathrm{F}_{2}$-derived $\mathrm{F}_{3}$ lines. About $20 \mathrm{BC}_{1} \mathrm{~F}_{3}$ or $\mathrm{BC}_{2} \mathrm{~F}_{3}$ substitution (both disomic and monosomic) lines from each cross (two families within each cross, each carrying 10 lines) were grown during the 1994 and 1995 crop seasons at El Batan research station and tested for resistance with races TBD/TM and MCJ/SP, respectively (Table 3). The plot sizes, planting, and inoculation procedures were the same as described for genetic analysis. The 'Lalbahadur' monosomics and 'Pavon 76' were included as parental checks. The lines were classified for leaf rust response. It is expected that in a cross involving the critical chromosome (chromosome carrying the resistance gene), the disomic substitution $\mathrm{F}_{3}$ lines (those derived from $2 n=42$ plants) will be homozygous resistant, because the substituted chromosome pair carries the resistance gene in homozygous state from the resistant parent. The monosomic substitution lines (those derived from $2 n=41$ plants) in a critical cross will segregate, because a few susceptible plants with $2 n=40$ will lack the resistance allele, and the plants with $2 n=41$ could be partially resistant if resistance is not completely dominant (as the case is in our study). Homozygous-susceptible $\mathrm{F}_{3}$ lines, derived mostly from $2 n=40$ plants, are rarely expected in a critical cross, because the nullisomic plants are usually eliminated from the $\mathrm{F}_{2}$ populations because of the lack of vigor or male sterility (14). In noncritical crosses, the substitution $F_{3}$ lines from the backcrosses could be distributed in all three categories in a Mendelian segregation ratio, or all could be homozygous susceptible, depending on the number of backcrosses and the probability of the carry-

TABLE 2. Distribution of $\mathrm{F}_{3}$ and $\mathrm{F}_{5}$ lines in the crosses of adult leaf rust-resistant wheat cultivar Pavon 76 with leaf rust susceptible 'Jupateco $73 \mathrm{~S}$ ' and 'Avocet $\mathrm{S}$ '

\begin{tabular}{|c|c|c|c|c|c|c|c|c|c|c|}
\hline \multirow[b]{2}{*}{ Cross } & \multirow[b]{2}{*}{ Generation } & \multirow[b]{2}{*}{ Season tested } & \multirow[b]{2}{*}{ Pathotype } & \multicolumn{4}{|c|}{ Number of lines with reaction $^{a}$} & \multirow[b]{2}{*}{$\chi^{2}$ value $^{b}$} & \multirow[b]{2}{*}{$P^{\mathrm{c}}$} & \multirow[b]{2}{*}{ Number of genes } \\
\hline & & & & HPTR & HPTS & SegI & SegS & & & \\
\hline 'Jupateco 73S' × 'Pavon 76' & $\mathrm{F}_{3}$ & 1991 & TBD/TM & 4 & 4 & 43 & 67 & 4.21 & $>0.10$ & 2 \\
\hline 'Jupateco 73S' × 'Pavon 76' & $\mathrm{F}_{5}$ & $1992-1993$ & TBD/TM & 17 & 23 & 58 & 20 & 3.25 & $>0.25$ & 2 \\
\hline 'Avocet $S^{\prime} \times$ 'Pavon 76' & $\mathrm{F}_{3}$ & $1995-1996$ & $\mathrm{MCJ} / \mathrm{SP}$ & 7 & 9 & 61 & 71 & 1.22 & $>0.75$ & 2 \\
\hline 'Avocet S' × 'Pavon 76' & $\mathrm{F}_{5}$ & 1996-1997 & $\mathrm{MCJ} / \mathrm{SP}$ & 29 & 26 & 72 & 19 & 0.20 & $>0.95$ & 2 \\
\hline
\end{tabular}

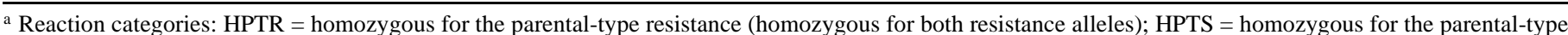
susceptibility (homozygous, lacking both resistance alleles); SegI = either segregating or homozygous for disease levels higher than that of the resistant parent, but less than that of the susceptible parent (homozygous for one resistance allele, the second resistance allele either absent or present in heterozygous condition); SegS = segregating with disease levels reaching the susceptible parent response (heterozygous for one resistance allele and the second resistance allele absent; or heterozygous for both resistance alleles).

${ }^{\mathrm{b}} \chi^{2}$ values for ratios HPTR/HPTS/SegI/SegS $(1: 1: 6: 8)$ in $\mathrm{F}_{3}$ and HPTR/HPTS/SegI/SegS (0.1914:0.1914:0.4922:0.1251) in F .

c $P$ values higher than 0.05 indicate nonsignificant values of $\chi^{2}$. 
over of resistance allele from one backcross generation to the next. Testing of these substitution $\mathrm{F}_{3}$ lines from one or two backcrosses can help identify several noncritical chromosomes, which can be eliminated from further backcrossing. Based on results obtained during the 1994 and 1995 seasons, we made one additional backcross and grew $\mathrm{BC}_{2}$ or $\mathrm{BC}_{3}$-derived substitution $\mathrm{F}_{3}$ lines from 10 crosses during the 1996 season at El Batan and tested them using race $\mathrm{MCJ} / \mathrm{SP}$ (Table 4) to verify earlier results on the chromosomal location of resistance.

The 'Lalbahadur' monosomics and one apparently critical chromosome in the substitution work were diagnosed for their correct identification using the modified giemsa C-banding technique (7).
We have excluded the results for chromosomes 1A, 3A, 4A, 1D, and $3 \mathrm{D}$, because they were identified as being incorrect.

The disomic 'Lalbahadur' ('Pavon 1B') chromosome substitution lines and the parents were grown in the field during the 1997 season at El Batan, inoculated with race $\mathrm{MCJ} / \mathrm{SP}$, and evaluated for leaf rust progress four times at weekly intervals (Fig. 1).

\section{RESULTS AND DISCUSSION}

Genetic analysis. 'Pavon 76' displayed between 5 and $10 \%$ leaf rust severity when the susceptible parents 'Jupateco 73S' and 'Avocet $S^{\prime}$ displayed approximately 80 to $100 \%$ leaf rust (Table 1),

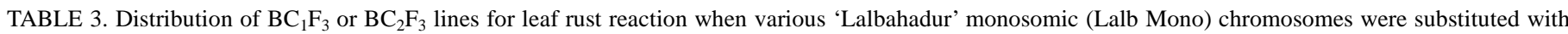
respective chromosomes from 'Pavon 76', tested during 1994 and 1995 using Puccinia recondita f. sp. tritici pathotypes TBD/TM and MCJ/SP, respectively

\begin{tabular}{|c|c|c|c|c|c|c|c|}
\hline \multirow[b]{3}{*}{ Substitution } & \multirow[b]{3}{*}{ Year tested } & \multicolumn{6}{|c|}{ Number of lines with reaction ${ }^{\mathrm{a}}$} \\
\hline & & \multicolumn{3}{|c|}{ Family $1^{\text {b }}$} & \multicolumn{3}{|c|}{ Family $2^{b}$} \\
\hline & & HR & Seg & HS & HR & Seg & HS \\
\hline \multirow[t]{2}{*}{ Lalb Mono 2A*3/'Pavon 76' } & 1994 & 4 & 2 & 3 & 3 & 4 & 2 \\
\hline & 1995 & 3 & 3 & 3 & 2 & 4 & 1 \\
\hline \multirow[t]{2}{*}{ Lalb Mono 5A*3/'Pavon76’' } & 1994 & 0 & 0 & 10 & 0 & 0 & 10 \\
\hline & 1995 & 0 & 0 & 10 & 0 & 0 & 10 \\
\hline \multirow[t]{2}{*}{ Lalb Mono 6A*3/‘Pavon76’ } & 1994 & 0 & 0 & 10 & 0 & 0 & 10 \\
\hline & 1995 & 0 & 0 & 10 & 0 & 1 & 9 \\
\hline \multirow[t]{2}{*}{ Lalb Mono 7A*3/'Pavon76’ } & 1994 & 0 & 0 & 10 & 0 & 0 & 10 \\
\hline & 1995 & 0 & 0 & 10 & 0 & 0 & 10 \\
\hline \multirow[t]{2}{*}{ Lalb Mono 1B*3/'Pavon76’ } & 1994 & 3 & 7 & 0 & 5 & 5 & 0 \\
\hline & 1995 & 3 & 7 & 0 & 5 & 5 & 0 \\
\hline \multirow[t]{2}{*}{ Lalb Mono 2B*3/'Pavon76’ } & 1994 & 0 & 0 & 9 & 2 & 4 & 4 \\
\hline & 1995 & 0 & 0 & 9 & 2 & 3 & 5 \\
\hline \multirow[t]{2}{*}{ Lalb Mono 3B*3/‘Pavon76’ } & 1994 & 0 & 0 & 10 & 2 & 7 & 1 \\
\hline & 1995 & 0 & 0 & 10 & 3 & 7 & 0 \\
\hline \multirow[t]{2}{*}{ Lalb Mono 4B*3/‘Pavon76’' } & 1994 & 0 & 0 & 10 & 1 & 6 & 3 \\
\hline & 1995 & 0 & 0 & 10 & 2 & 7 & 1 \\
\hline \multirow[t]{2}{*}{ Lalb Mono 5B*2/‘Pavon76’ } & 1994 & 2 & 7 & 1 & 1 & 8 & 1 \\
\hline & 1995 & 4 & 5 & 1 & 2 & 7 & 1 \\
\hline \multirow[t]{2}{*}{ Lalb Mono 6B*3/'Pavon76’ } & 1994 & 0 & 0 & 10 & 0 & 0 & 10 \\
\hline & 1995 & 0 & 0 & 10 & 0 & 0 & 10 \\
\hline \multirow[t]{2}{*}{ Lalb Mono 7B*3/'Pavon76’' } & 1994 & 0 & 8 & 2 & 0 & 1 & 8 \\
\hline & 1995 & 0 & 8 & 2 & 0 & 2 & 8 \\
\hline \multirow[t]{2}{*}{ Lalb Mono 2D*2/‘Pavon76’' } & 1994 & 5 & 2 & 3 & 2 & 2 & 6 \\
\hline & 1995 & 4 & 3 & 3 & 2 & 3 & 5 \\
\hline \multirow[t]{2}{*}{ Lalb Mono 4D*3/‘Pavon76’ } & 1994 & 2 & 5 & 3 & 10 & 0 & 0 \\
\hline & 1995 & 2 & 5 & 3 & 10 & 0 & 0 \\
\hline \multirow[t]{2}{*}{ Lalb Mono 5D*2/'Pavon76’' } & 1994 & 4 & 5 & 1 & 0 & 0 & 10 \\
\hline & 1995 & 3 & 6 & 1 & 0 & 0 & 10 \\
\hline \multirow[t]{2}{*}{ Lalb Mono 6D*3/'Pavon76’ } & 1994 & 1 & 3 & 6 & 1 & 4 & 5 \\
\hline & 1995 & 0 & 4 & 6 & 1 & 5 & 4 \\
\hline \multirow{2}{*}{ Lalb Mono 7D*3/'Pavon 76' } & 1994 & 0 & 0 & 10 & 0 & 4 & 6 \\
\hline & 1995 & 0 & 0 & 10 & 0 & 6 & 4 \\
\hline
\end{tabular}

a Reaction categories: $\mathrm{HR}=$ homozygous resistant, $\mathrm{Seg}=$ segregating, and $\mathrm{HS}=$ homozygous susceptible.

${ }^{\mathrm{b}}$ Families 1 and 2 were derived from two different monosomic $(2 n=41) \mathrm{BC}_{1}$ or $\mathrm{BC}_{2}$ plants.

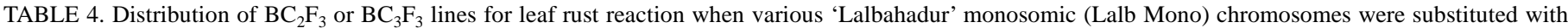
respective chromosomes from 'Pavon 76', tested during 1996 using Puccinia recondita f. sp. tritici pathotype MCJ/SP

\begin{tabular}{|c|c|c|c|c|c|c|c|c|c|}
\hline \multirow[b]{3}{*}{ Substitution } & \multicolumn{9}{|c|}{ Number of lines with reaction $^{\mathrm{a}}$} \\
\hline & \multicolumn{3}{|c|}{ Family $1^{\mathrm{b}}$} & \multicolumn{3}{|c|}{ Family $2^{b}$} & \multicolumn{3}{|c|}{ Family $3^{b}$} \\
\hline & HR & Seg & HS & HR & Seg & HS & HR & Seg & HS \\
\hline Lalb Mono 2A*4/'Pavon 76' & 0 & 0 & 14 & 3 & 5 & 5 & $\ldots^{\mathrm{c}}$ & $\ldots$ & $\ldots$ \\
\hline Lalb Mono 5A*4/'Pavon 76' & 0 & 0 & 14 & 0 & 0 & 14 & 0 & 0 & 14 \\
\hline Lalb Mono 6A*4/'Pavon 76' & 0 & 0 & 14 & 0 & 0 & 14 & $\ldots$ & $\ldots$ & $\ldots$ \\
\hline Lalb Mono 1B*4/'Pavon 76' & 1 & 13 & 0 & 3 & 11 & 0 & 2 & 12 & 0 \\
\hline Lalb Mono 5B*3/'Pavon 76' & 2 & 8 & 4 & 0 & 0 & 14 & $\ldots$ & $\ldots$ & $\ldots$ \\
\hline Lalb Mono 7B*4/'Pavon 76' & 0 & 0 & 14 & 0 & 0 & 14 & 0 & 0 & 14 \\
\hline Lalb Mono 2D*3/'Pavon 76' & 6 & 8 & 0 & 4 & 9 & 1 & 4 & 12 & 0 \\
\hline Lalb Mono 5D*3/'Pavon 76' & 6 & 6 & 2 & 3 & 5 & 6 & 0 & 0 & 14 \\
\hline Lalb Mono 6D*4/'Pavon 76' & 0 & 0 & 14 & 0 & 0 & 14 & 0 & 0 & 14 \\
\hline Lalb Mono 7D*4/'Pavon 76' & 0 & 0 & 14 & 0 & 0 & 14 & 0 & 0 & 14 \\
\hline
\end{tabular}

a Reaction categories: HR = homozygous resistant, $\mathrm{Seg}=$ segregating, and HS = homozygous susceptible.

${ }^{\mathrm{b}}$ Families 1, 2, and 3 were derived from three different monosomic $(2 n=41) \mathrm{BC}_{2}$ or $\mathrm{BC}_{3}$ plants.

${ }^{\mathrm{c}}$ Not tested. 
indicating that the adult-plant resistance of 'Pavon 76' was easily distinguished in each season. The $\mathrm{F}_{1}$ plants from the cross 'Jupateco 73S' $\times$ 'Pavon 76' displayed about 30\% leaf rust severity as compared with 5\% for 'Pavon 76' and 100\% for 'Jupateco 73S' during the 1991 season. This indicated that resistance was partially dominant. In all seasons, 'Pavon 76' matured with disease ratings of 30 to $40 \%$ (Fig. 1, the 1997 crop season). The uredinia on 'Pavon 76' were scored as moderately susceptible to susceptible (moderate to large uredinia without chlorosis or necrosis), compared with susceptible (large uredinia without chlorosis or necrosis) for 'Jupateco $73 \mathrm{~S}$ ' and 'Avocet S' (Table 1), which indicates the compatible nature of response to infection, a known feature of slow-rusting or partial resistance $(3,10)$.

Frequency distributions of leaf rust severity in $\mathrm{F}_{5}$ lines at first evaluation are shown in Figures 2 and 3 for 'Jupateco $73 \mathrm{~S}$ ' $\times$ 'Pavon 76' and 'Avocet S' $\times$ 'Pavon 76' crosses, respectively. The lines were distributed continuously. Distributions of $\mathrm{F}_{3}$ and $\mathrm{F}_{5}$ lines in both crosses were in accordance to ratios expected for segregation at two independent loci, assuming that the two resistance alleles acted in additive manner (Table 2). These assumptions were made because $1 / 16$ of the $F_{3}$ lines and about $19 \%$ of the $F_{5}$ lines were phenotypically similar to the resistant or susceptible parent's response. Race selection in studies conducted in different years did not influence the estimation of the number of resistance genes. From these results, we conclude that the slow-rusting resistance of 'Pavon 76' is based on the additive effects of two genes. Our conclusion that the slow-rusting resistance to leaf rust involves a few additive genes is congruent with those published earlier $(1,2,8,22)$.

Because both 'Pavon 76' and 'Avocet S' carry race-specific genes Lr10 and Lrl3 (21; R. P. Singh, unpublished data), the $\mathrm{F}_{3}$ and $\mathrm{F}_{5}$ lines derived from their crosses are expected to be homozygous. Therefore, the two additive genes involved in the slow-rusting resistance of 'Pavon 76' are different from $\mathrm{Lr} 10$ and $\mathrm{Lr} 13$. Genes LrIO and Lrl3 are expected to be ineffective because of the presence of virulence in the $P$. recondita f. sp. tritici races we used.

Chromosomal location of resistance. Evaluations of the 'Lalbahadur' monosomics for leaf rust resistance indicated that monosomics for chromosomes $2 \mathrm{D}$ and 4D were resistant to leaf rust, and monosomics for 2A and 5D segregated. This implies that results for crosses involving these monosomics require careful interpretation. The remaining monosomics were similar in their susceptibility to cultivars Lalbahadur, Jupateco 73S, and Avocet $\mathrm{S}$.

Distribution of leaf rust reactions of $\mathrm{BC}_{1} \mathrm{~F}_{3}$ or $\mathrm{BC}_{2} \mathrm{~F}_{3}$ lines in 16 substitutions (both monosomic and disomic) is given in Table 3. Results for substitutions involving chromosomes 1A, 3A, 4A, 1D, and $3 \mathrm{D}$ are not presented, because 'Lalbahadur' monosomics for

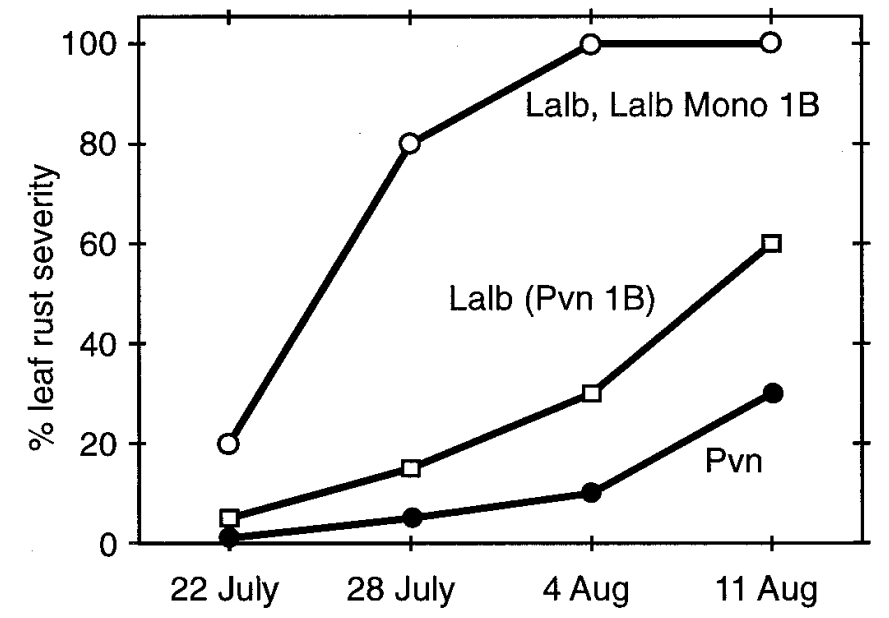

Fig. 1. Progress of leaf rust on 'Pavon 76' (Pvn), 'Lalbahadur' (Lalb), 'Lalbahadur' monosomic 1B (Lalb Mono 1B), and 'Lalbahadur' ('Pavon 1B') disomic chromosome substitution lines observed during the 1997 season. these chromosomes were identified as being incorrect by the $\mathrm{C}$ banding diagnostic. Chromosome 1B of 'Pavon 76' appeared to be critical, because the $\mathrm{F}_{3}$ lines were either homozygous resistant or segregating. In all other substitutions, the $F_{3}$ lines were either homozygous susceptible or segregation occurred and homozygoussusceptible lines were observed frequently. One family in the substitution involving 'Lalbahadur' monosomic 4D had all homozygousresistant lines. This was to be expected, because the monosome itself was resistant (Table 1); therefore, backcrosses resulted in recovering the parental resistance phenotype of the monosome parent. Based on these results, we infer that several chromosomes either did not carry the resistance gene or may have lost the targeted chromosome from 'Pavon 76' through the transmission of male gametes with $n=20$ chromosomes. In either case, further backcrossing may not be desirable, because similar results will be obtained. Results for $\mathrm{F}_{3}$ lines of 10 substitutions derived from one additional backcross to the 'Lalbahadur' monosomic are summarized in Table 4. Because $\mathrm{BC}_{3} \mathrm{~F}_{3}$ lines in each of the three families for the substitution involving chromosome $1 \mathrm{~B}$ were either homozygous resistant or segregating, it was again evident that chromosome 1B of 'Pavon 76' carried the resistance allele. Segregation for resistance in substitutions involving chromosomes $2 \mathrm{~A}, 2 \mathrm{D}$, and $5 \mathrm{D}$ is due to the fact that these 'Lalbahadur' monosomics were not susceptible (Table 1). Most segregating lines in the 'Lalbahadur' 1B substitution lacked completely susceptible plants. This is to be

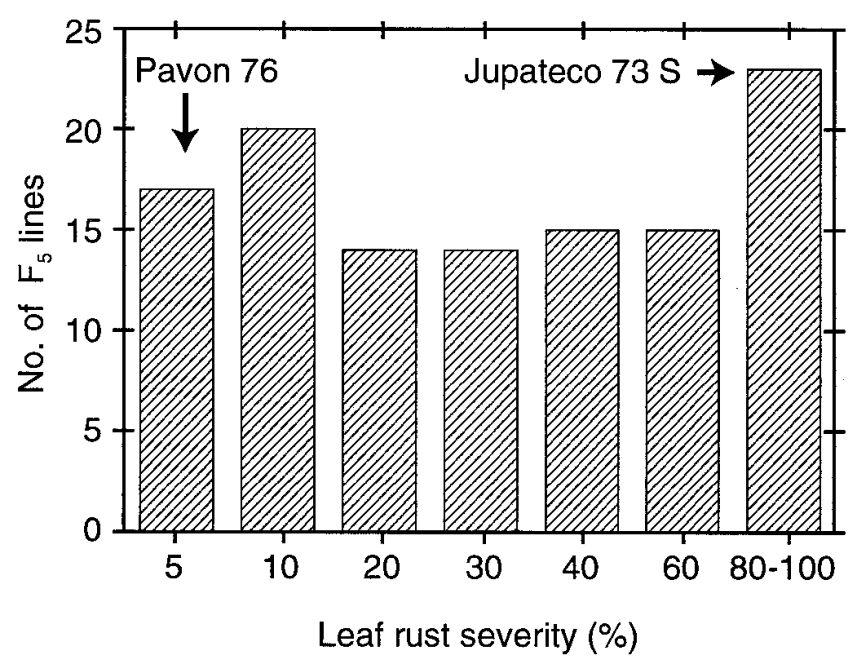

Fig. 2. Frequency distribution of adult-plant leaf rust severities of $118 \mathrm{~F}_{5}$ lines from the cross 'Jupateco 73S' $\times$ 'Pavon 76'.

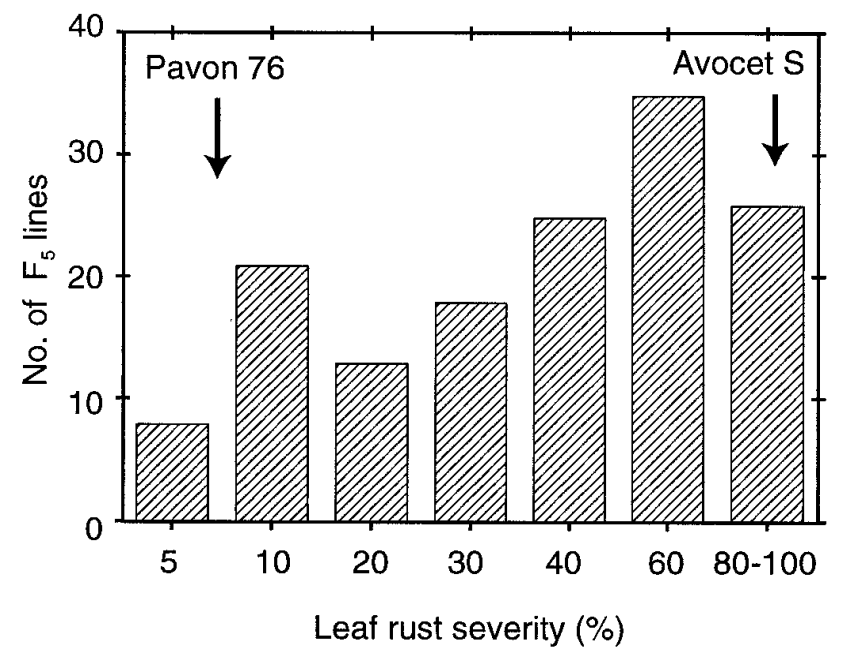

Fig. 3. Frequency distribution of adult-plant leaf rust severities of $146 \mathrm{~F}_{5}$ lines from the cross 'Avocet S' $\times$ 'Pavon 76'. 
expected if resistance is partially effective in hemizygous chromosomal state (i.e., only one copy of the resistance gene is present in the plant). The rare susceptible plants in segregating families are, therefore, either nullisomic $(2 n=40)$ or secondary aneuploids as a consequence of chromosomal misdivision.

The chromosomal status of all 6 homozygous resistant and 10 randomly chosen segregating $\mathrm{BC}_{3} \mathrm{~F}_{3}$ lines from the chromosome $1 \mathrm{~B}$ substitution (in the cross 'Lalbahadur' monosomic $1 \mathrm{~B} * 4 \times$ 'Pavon 76'; Table 4) was determined by doing mitotic root tip counts on five seedlings per line. If all five seedlings were disomic $(2 n=42)$, we interpreted that the line was derived from a disomic plant. But if at least two of the five seedlings had chromosome counts of $2 n=$ 41 or 40, we inferred that the line was derived from a monosomic plant. As expected, all six homozygous-resistant lines were disomic, and all segregating lines were derived from monosomic plants. Monosomic plants from segregating families were C-banded to validate the status of chromosome $1 \mathrm{~B}$ and ratify our results. The observations for chromosome 1B were correct. Therefore, we conclude that one of the two slow-rusting genes present in 'Pavon 76' is located on chromosome 1B and designated as Lr46. Chromosomal arm location is currently not possible because of the unavailability of a susceptible monotelosomic series. However, we are developing populations suitable for identifying the linked molecular marker to establish chromosomal arm location. The disomic $\mathrm{BC}_{3} \mathrm{~F}_{3}$ lines (Table 4) could be called 'Lalbahadur' ('Pavon 1B') chromosome substitution lines and used as tester lines for gene Lr46. These lines have about $94 \%$ recovery of the 'Lalbahadur' genotype for 20 other chromosomes and are expected to possess gene Lrl, because both the 'Lalbahadur' and 'Pavon 76' parents carry it. This should not pose any major problem in testing the usefulness of $L r 46$ at other sites, because virulence for $L r l$ is common in most areas of the world.

Because the substitution of chromosome 7D of 'Pavon 76' in 'Lalbahadur' did not confer any resistance (Tables 3 and 4), we conclude that it lacked the slow-rusting gene Lr34 located on chromosome 7DS (4). This result is in agreement with Singh (18), who inferred the absence of Lr34 in 'Pavon 76' from the absence of leaf tip necrosis, which is tightly linked to it (17). Therefore, gene Lr46 is the second named gene conferring slow rusting to leaf rust in wheat.

Our genetic analysis results have shown that 'Pavon 76' contains two slow-rusting genes. However, in the current study, we were unable to determine the chromosomal location of the second gene. There are three possible reasons for this failure: (i) the second gene may be located on one of the five chromosomes for which information is lacking; (ii) the targeted chromosome of 'Pavon 76' may have been missed because of transmission of a 20 chromosome male gamete, since we used monosomic plants as male parents in backcrossing onto 'Lalbahadur' monosomics; and (iii) the second gene may also be located on chromosome 1B, on the opposite arm, or further away on the same arm. The third possibility can be ruled out, because disease progressed much faster on 'Lalbahadur' ('Pavon 1B') chromosome substitution lines than on 'Pavon 76', which carried both slow-rusting genes (Fig. 1). This result further indicates that the presence of the single slow-rusting gene Lr46 does not give enough protection under high leaf rust pressure, as the last rating of $60 \%$ (Fig. 1) was too high for acceptance in breeding programs. The gene must be present in combination with other slow-rusting genes of additive effects to impart adequate resistance, as seen earlier with gene Lr34 (22).

\section{ACKNOWLEDGMENTS}

We thank R. A. McIntosh for providing the 'Lalbahadur' monosomic series and A. McNab for editorial review of the manuscript.

\section{LITERATURE CITED}

1. Bjarko, M. E., and Line, R. F. 1988. Quantitative determination of the gene action to leaf rust resistance in four cultivars of wheat, Triticum aestivum. Phytopathology 78:451-456.

2. Broers, L. H. M., and Jacobs, T. 1989. The inheritance of host plant effect on latency period of wheat leaf rust in spring wheat. II: Number of segregating factors and evidence for transgressive segregation in $\mathrm{F}_{3}$ and $\mathrm{F}_{5}$ generations. Euphytica 44:207-214.

3. Caldwell, R. M. 1968. Breeding for general and/or specific plant disease resistance. Pages 263-272 in: Proc. Int. Wheat Genetics Symp., 3rd. K. W. Finlay and K. W. Shepherd, eds. Australian Academy of Science, Canberra.

4. Dyck, P. L. 1987. The association of a gene for leaf rust resistance with the chromosome 7D suppressor of stem rust resistance in common wheat. Genome 29:467-469.

5. Dyck, P. L. 1991. Genetics of adult-plant leaf rust resistance in "Chinese Spring" and "Sturdy" wheats. Crop Sci. 31:309-311.

6. Huerta-Espino, J., and Singh, R. P. 1996. Misconceptions on durability of some adult leaf rust resistance genes in wheat. Pages 109-111 in: Proc. Eur. Mediterr. Cereal Rusts Mildews Conf., 9th. G. H. J. Kema, R. E. Niks, and R. A. Daamen, eds. IPO-DLO, Wageningen, the Netherlands.

7. Jahan, Q., Ter-Kuile, N., Hashmi, N., Aslam, M., Vahidy, A. A., and Mujeeb-Kazi, A. 1990. The status of the 1B/1R translocation chromosome in some released wheat varieties and the 1989 candidate varieties of Pakistan. Pak. J. Bot. 22:1-10.

8. Kuhn, R. C., Ohm, H. W., and Shaner, G. 1980. Inheritance of slow leafrusting resistance in Suwon 85 wheat. Crop Sci. 20:655-659.

9. Mujeeb-Kazi, A., and Miranda, J. L. 1985. Enhanced resolution of somatic chromosome constriction as an aid to identify intergeneric hybrids among some Triticeae. Cytologia 50:701-709.

10. Parlevliet, J. E. 1988. Strategies for the utilization of partial resistance for the control of cereal rusts. Pages 48-62 in: Breeding Strategies for Resistance to the Rusts of Wheat. N. W. Simmonds and S. Rajaram, eds. CIMMYT, Mexico City.

11. Peterson, R. F., Campbell, A. B., and Hannah, A. E. 1948. A diagrammatic scale for estimating rust severity on leaves and stems of cereals. Can. J. Res. Sect. C. 26:496-500.

12. Roelfs, A. P., Singh, R. P., and Saari, E. E. 1992. Rust Diseases of Wheat: Concepts and Methods of Disease Management. CIMMYT, Mexico City.

13. Sayre, K., Singh, R. P., Huerta-Espino, J., and Rajaram, S. 1998. Genetic progress in reducing losses to leaf rust in CIMMYT-derived Mexican spring wheat cultivars. Crop Sci. 38:654-659.

14. Sears, E. 1953. Nullisomic analysis in common wheat. Am. Nat. 87:245-252.

15. Sheen, S. J., and Snyder, L. A. 1964. Studies on the inheritance of resistance to six stem rust cultures using chromosome substitution lines of a Marquis wheat selection. Can. J. Genet. Cytol. 6:74-82.

16. Singh, R. P. 1991. Pathogenicity variations of Puccinia recondita f. sp. tritici in wheat-growing areas of Mexico during 1988 and 1989. Plant Dis. 75:790-794.

17. Singh, R. P. 1992 . Association between gene $\operatorname{Lr} 34$ for leaf rust resistance and leaf tip necrosis in wheat. Crop Sci. 32:874-878.

18. Singh, R. P. 1993. Resistance to leaf rust in 26 Mexican wheat cultivars. Crop Sci. 33:633-637.

19. Singh, R. P., and Gupta, A. K. 1992. Expression of wheat leaf rust resistance gene Lr34 in seedlings and adult plants. Plant Dis. 76:489-491.

20. Singh, R. P., and Huerta-Espino, J. 1995. Inheritance of seedling and adult plant resistance to leaf rust in wheat cultivars Ciano 79 and Papago 86. Plant Dis. 79:35-38

21. Singh, R. P., and Rajaram, S. 1991. Resistance to Puccinia recondita f. sp. tritici in 50 Mexican bread wheat cultivars. Crop Sci. 31:1472-1479.

22. Singh, R. P., and Rajaram, S. 1992. Genetics of adult-plant resistance to leaf rust in 'Frontana' and three CIMMYT wheats. Genome 35:24-31. 